\title{
Research on the Emergency Shelter Accessibility in Urban Communities Bo Tang ${ }^{1, *}$, Danni Wang ${ }^{1}$, Yun Song ${ }^{1}$, Jinan Qiu ${ }^{2}$, Yongtao Yan ${ }^{3}$, Zhihuan Zhang ${ }^{4}$ \\ ${ }^{1}$ Department of Resources and the Urban Planning, Xinhua College of Sun Yat-sen University, Guangzhou 510520, China \\ ${ }^{2}$ School of Geography and Planning, Sun Yat-sen University, Guangzhou 510520, China \\ ${ }^{3}$ Guangzhou Urban Planning \& Design Survey Research Institute, Guangzhou 510520, China \\ ${ }^{4}$ Earthquake Monitoring Centre of Guangzhou city, Guangzhou 510520, China
}

Received 13 November 2017

Accepted 13 December 2017

\begin{abstract}
The reasonable planning of emergency shelter in urban communities is one of the important means of disaster prevention. Using the improved Two-Step floating catchment area method and GIS, this paper analyzes the accessibility of emergency shelter in Yuexiu district under microcosmic perspective. The conclusions are as follows: Firstly, the total amount and type of emergency shelter are abundant in Yuexiu district, per capita emergency shelter is high, but spatial distribution is unreasonable; Secondly, the overall accessibility of emergency shelter is poor, north region better than south region, and supply and demand ratio is an important factor about the difference of accessibility; Thirdly, when d0 to $1500 \mathrm{~m}$, emergency shelter accessibility reaches the maximum and proportion of service area is the best. The related conclusions can provide some reference for the optimization and planning of emergency shelter in Yuexiu district.
\end{abstract}

Keywords: Emergency shelter, accessibility, Two-Step floating catchment area method, GIS, Yuexiu district

\section{城市社区应急避难场所空间可达性研究}

唐波 ${ }^{1, *}$, 王丹妮 ${ }^{1}$, 宋云 ${ }^{1}$, 邱锦安 ${ }^{2}$, 间永涛 ${ }^{3}$, 张志欢 ${ }^{4}$

1. 中山大学新华学院资源与城乡规划系, 广州 510520, 中国

2. 中山大学地理科学与规划学院, 广州 510520, 中国

3. 广州市城市规划勘测设计研究院，广州 510520, 中国

4. 广州市地震监测中心，广州 510520，中国

\begin{abstract}
摘要: 合理规划和布局社区应急避难场所是城市防灾减灾的重要手段之一。利用改进的两步移动搜寻法和 GIS 空间技术，微观视角下对广州市越秀区应急避难场所进行空间布局和可达性研究。结果表明：越秀区应急避难场 所总量和类型较为丰富, 人均应急避难场所有效面积较高, 但空间分布不合理; 应急避难场所可达性总体较差, 并呈现出明显的南北差异, 北部可达性优于南部, 其中供求比率是导致可达性空间差异的重要因素; 通过对比分 析得出 $1500 \mathrm{~m}$ 是越秀区应急避难场所适宜的服务半径, 可达性最高, 服务面积比例最佳。最后提出相关建议, 可为越秀区应急避难场所的优化与规划提供参考。
\end{abstract}

关键词：应急避难场所，可达性，两步移动搜寻法, GIS，越秀区

城市作为人口密集和经济密度高的区域，由于受 到自然灾害和人为灾害的双重干扰，面临较大的灾害 风险。城市应急避难场所作为城市救灾和防灾的重要

\footnotetext{
*Corresponding Author:E-mail: tballen196@163.com
}

组成部分, 随着城市化进程的不断加快, 对应急避难 场所的需求、建设和管理有了新的审视和反思, 其选

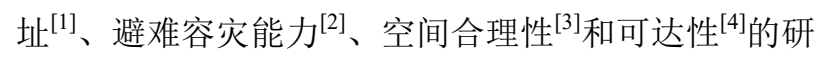
究逐渐引起了国内外学者的关注。其中空间可达性测 度最大的优点在于能够非常直观的揭示公共服务设施 
空间分布的均衡性, 能够清晰地判断公共服务供给过 度、匹配和不足的地区 ${ }^{[5]}$, 是评价应急避难场所空间 分布是否合理的重要方法。可达性最早由美国学者 Hansen提出, 应用于交通网络节点的便捷程度评价 ${ }^{[6]}$, 指从事某项活动时到达某一空间位置的便捷度, 即从 一个地方到另一个地方过程中克服困难的难易程度, 常用时间成本、距离成本、经济成本等指标来表达 ${ }^{[7]}$ 。 目前国内外学者利用缓冲区分析法、潜能模型、GIS 分析法和两步移动搜寻法对城市绿地公园 ${ }^{[8]}$ 、医疗设 施 ${ }^{[5]}$ 、旅游景点 ${ }^{[9]}$ 和应急避难场所 ${ }^{[10]}$ 等公共服务设施的 可达性做了较多的探索。其中两步移动搜寻法使用最 多, 该方法考虑了所有能为消费者提供服务的多个供 给点, 又测度了消费者的对公共服务的可获得性, 重 点关注供给点的供需比 ${ }^{[11]}$ 。所以在城市应急救援管理 中, 也须考虑居民需求与避难场所的容量, 同时关注 灾害发生时人群选择最近的应急避难场所的可达性研 究。但现有的应急避难场所研究大多成果从宏观和中 观尺度进行分析, 社区等微观尺度的研究较少 ${ }^{[12]}$ 。社 区作为我国城市管理的最小行政单位, 却承担整个社 会主体的最大单元, 囊括了地理区位、人口特点、交 通指引、生态环境等诸多方面因素。从社区的尺度研 究应急避难场所建设, 做到合理的空间布局和优化管 理, 有利于完善省、市应急避难场所规划 ${ }^{[13]}$ 。

越秀区是广州老三区之一, 人口密度大, 建筑物 密集, 路况复杂, 在应急管理和救援过程面临较大挑 战。本文基于两步移动搜寻法, 对服务供给点、距离 阈值等方面进行了改良, 同时结合GIS空间分析法, 微 观视角下对越秀区应急避难场所资源的可达性进行研 究, 以期为越秀区应急避难场所空间合理性和优化管 理提供相关决策依据。

\section{1. 区域概况和数据来源}

1.1 区域概况

越秀区位于广州市中心城区, 总面积 $33.8 \mathrm{~km}^{2}$ 。 2015 年末常住人口 115.68 万人, 户籍人口 117.48 万人, 是广州市面积最小、人口密度最高的市属城区。下辖 流花、洪桥、六榕等 18 个街道, 下设 222 个社区。

\section{2 数据来源}

应急避难场所资源的信息主要通过调研资料提
取, 街道数据和人口数据来自于越秀区 2016 年统计年 鉴, 其他数据和标准还参考了《广州市地震应急避难 场所专项规划纲要》。越秀区应急避难资源相对比较充 足, 人均有效面积为 $2.39 \mathrm{~m}^{2}$, 高于全国平均水平的 $1.5 \mathrm{~m}^{2}$ 。

\section{2. 研究方法}

两步移动搜寻法是由 Radke 和 $\mathrm{Mu}$ 在 2000 年提出, 是在早期移动搜寻法的基础上改进形成 ${ }^{[6]}$ 。该方法首 先设定一个阈值, 分别以供给地和需求地为基础, 分 别搜寻 2 次。对临界值内居民可以接近的资源或设施 数量进行比较, 一般数值越高, 可达性越好。该方法因 在使用过程中采用微观尺度如街道人口, 可以较好的 解决区域人口空间分布问题; 同时将避难场所分布的 数量、容量等情况纳入可达性评价, 更合理地考虑居 民与避难场所潜在的相互作用; 易于在 GIS 中操作的 3 个特点在应急避难场所可达性研究中具有明显优势 [14-15]。

第一步, 搜索所有位于应急避难场所 $\mathrm{j}$ 距离阈值 $\left(\mathrm{d}_{0}\right)$ 范围内街道质心 $(\mathrm{k})$, 计算出每个应急避难场所的供 需比 $\mathrm{R}_{j}$ 。主要是确定了应急避难场所的繁忙程度。

$$
R_{j}=\frac{S_{j}}{\sum_{k \in\left\{d_{k j} \leq d_{0}\right\}} P_{k}}
$$

式中, $\mathrm{P}_{k}$ 为搜寻区内街道 $\mathrm{k}\left(\right.$ 即 $\left.\mathrm{d}_{\mathrm{kj}} \leq \mathrm{d}_{0}\right)$ 的人口数; $S_{j}$ 为 $j$ 点的总供给; $d_{k j}$ 为位置 $k$ 和 $j$ 的距离。

第二步: 对每个街道质心 $\mathrm{i}$, 搜索所有距离阈值 $\left(\mathrm{d}_{0}\right)$ 内的避难场所 $(\mathrm{j})$, 将所有的供需比 $\mathrm{R}_{\mathrm{j}}$ 求和即得到街道 (i)的可达性 $A_{i}^{F}$ 。主要是计算了每个街道的可达性。

$$
A_{i}^{F}=\sum_{j \in\left\{d_{i j} \leq d_{0}\right\}} R_{j}=\sum_{k \in\left\{d_{k j} \leq d_{0}\right\}} \frac{S_{j}}{\sum_{k \in\left\{d_{k j} \leq d_{0}\right\}} P_{k}}
$$

式中, $A_{i}^{F}$ 为街道 $\mathrm{i}$ 对避难场所的空间可达性, 值越大 表明街道的可达性越好; $R_{j}$ 为街道 $i$ 搜寻区 $\left(d_{i j} \leqslant d_{0}\right)$ 内 避难场所 $\mathrm{j}$ 的供需比。按照广州市应急避难规划方案 要求, 紧急和固定性避难场所服务半径为 $500 \mathrm{~m} \sim 3000$ $\mathrm{m}$ ，即固定避难场所的影响范围为 $500 \mathrm{~m} \sim 3000 \mathrm{~m}$ 。因 此, 将搜寻阈值分别设为 $500 \mathrm{~m} 、 1000 \mathrm{~m} 、 1500 \mathrm{~m}$ 、 
$2000 \mathrm{~m} 、 2500 \mathrm{~m} 、 3000 \mathrm{~m}$ 。

由于本文采用的人口数据是以街道为单位, 人口 数据单位较大, 为得到微观尺度的人口数量分布, 首 先将研究范围进行格网化处理, 创建 $500 \mathrm{~m} * 500 \mathrm{~m}$ 大小 的规则格网单元, 然后对生成的格网提取中心点, 并 剔除位于道路、河流、公园绿地等不符合要求的一些 格网中心点, 最后篮选得出满足条件的 113 个需求点, 并将人口数据按比例分配到每个需求点上。

本文的避难供应点包含学校、体育场馆、公园绿 地和城市广场, 其中学校和体育场馆是点状数据, 而 公园绿地和城市广场是面状数据, 为满足两步移动搜
学校型在中部和东部数量较多; 大部分应急避难场所 资源都靠近主要道路。

\section{2 可达性分析}

基于以上步骤和图 1 的技术路线, 以 113 个街道 质点作为需求点, 以应急避难场所的出入口作为目的 地进行 2 次搜寻。第一步搜寻是以应急避难场所资源 为中心进行计算供需比 $R_{j}$ （图 4), 然后以需求点（街 道质心）为中心进行第二步搜寻，最后得到越秀区不 同 $\mathrm{d}_{0}$ 条件下的应急避难场所可达性空间分布结果（图 5 和表 1 )。结果表明: 1 ) 整体格局: 在 6 种 $\mathrm{d}_{0}$ 阈值

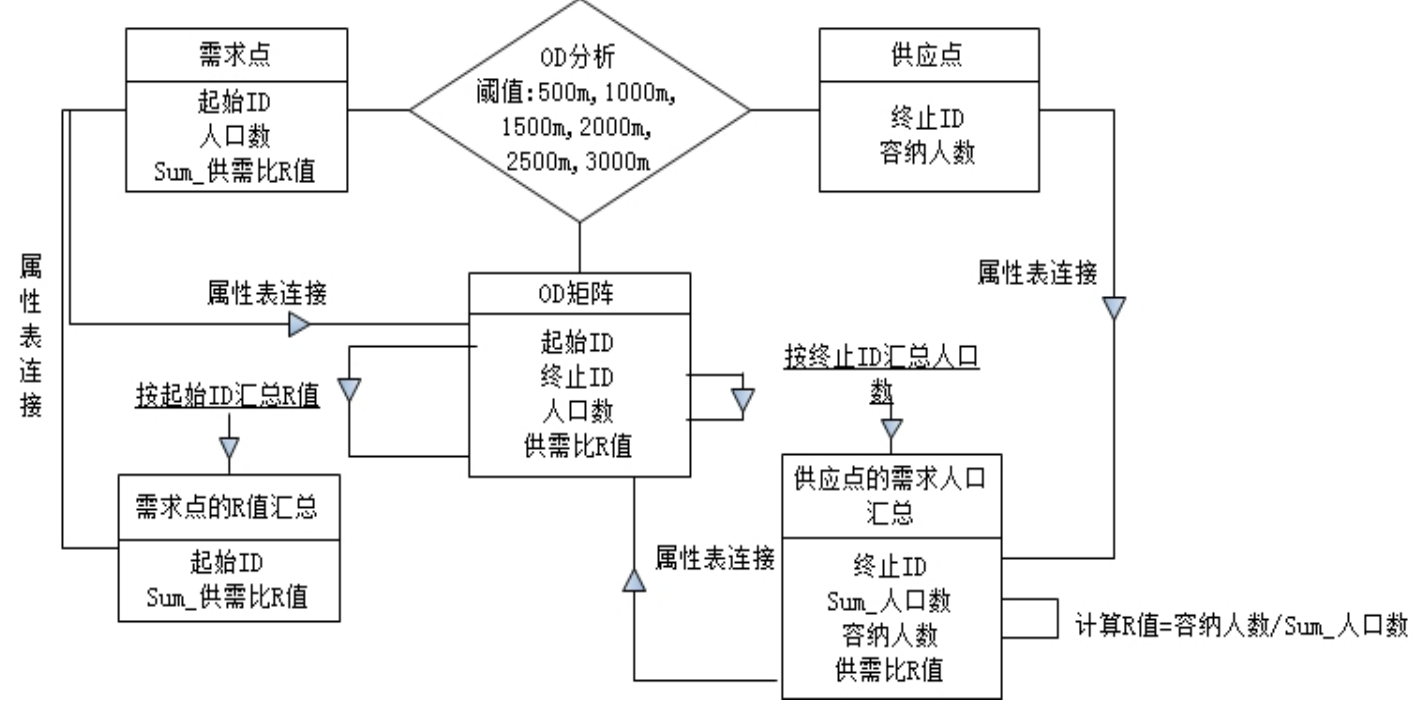

图 1. 技术路线图

寻算法的要求，提取城市广场面数据的质心作为该类 避难所的供给点, 而公园绿地以实际入口作为该类避 难所的供给点。具体技术路线见图 1。

\section{3. 结果分析}

3.1 应急避难场所资源空间分布特点

根据避难场所的面积要求以及避让地震断裂带、 地质隐患点、次生灾害源的选址要求, 进行篮选, 利 用 ArcGIS 软件建立数据库,包括公园绿地、城市广场、 学校、体育场馆 4 类, 得到越秀区现状可用作避难场 所的资源类型和空间图（如图 2 和图 3)。如图所示, 越秀区应急避难场所资源类型较多，包括公园绿地型、 广场型、学校型和体育场馆型, 主要为公园绿地型, 占所有应急避难场所资源的 $84.8 \%$ 。但分布相对比较 分散, 无明显集聚; 公园绿地型主要分布在南北两端,
下越秀区应急避难场所供需比和空间可达性呈现出明 显的南北差异, 北部可达性高于南部, 如登峰街道和 洪桥街道可达性较好。通过分析发现应急避难场所服 务的供求比率可达性的空间分布有一致性。2）1500m 服务半径在 6 中國值下的可达性最好, 服务面积比例 最佳。根据表 2 可知, $\mathrm{d}_{0}=1500$ 时, $A_{i}^{F}>12$ 的服务面积 达到 $2.38 \mathrm{~km}^{2}$, 占总面积的 $7 \%$ 。而当 $\mathrm{d}_{0}$ 为 $2000 \mathrm{~m}$ 和 3000 $\mathrm{m}$ 时, $A_{i}^{F}>12$ 的服务面积比例反而出现下降的趋势。3) 总体而言, 越秀区应急避难场所可达性较低。因为 6 种阈值下, 大部分街道的 $A_{i}^{F}$ 都处于 0-3 的范围, 占全 区面积的 $75 \%, A_{i}^{F}$ 大于 3 的服务范围偏少。所以尽管 越秀区人均避难场所面积较高, 但因为供求比率不均, 考虑到居民避难的可达距离后, 不能满足区域的整体 避难需求。 


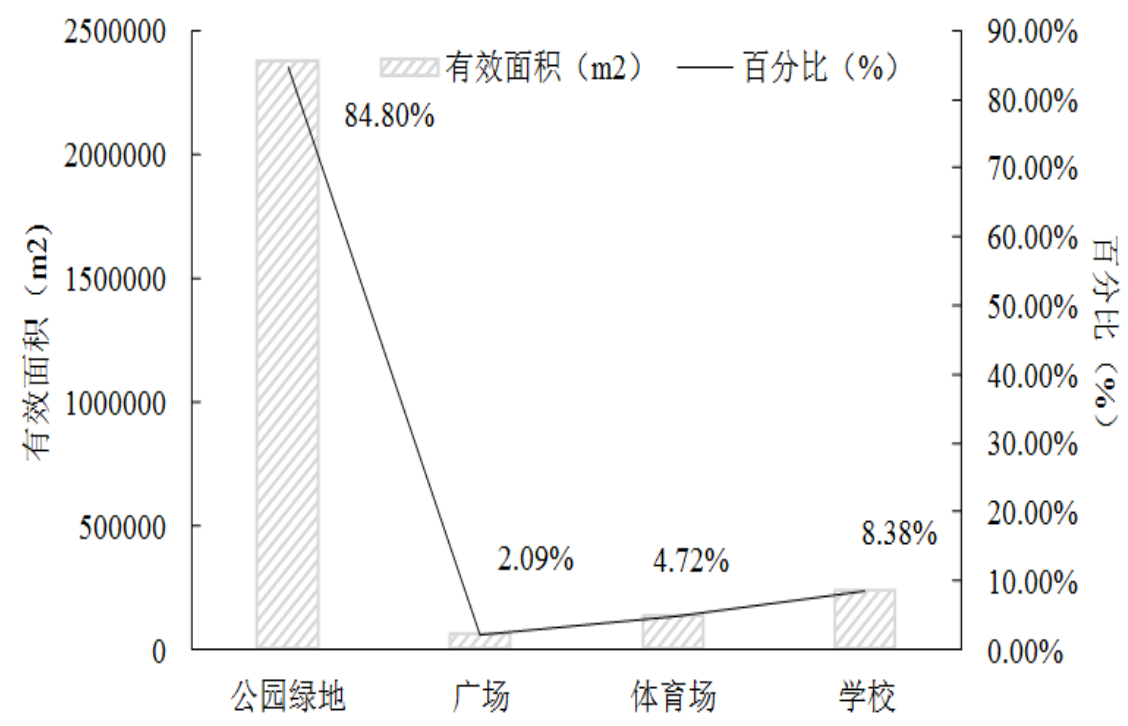

图 2. 广州越秀区应急避难场所资源类型分布图

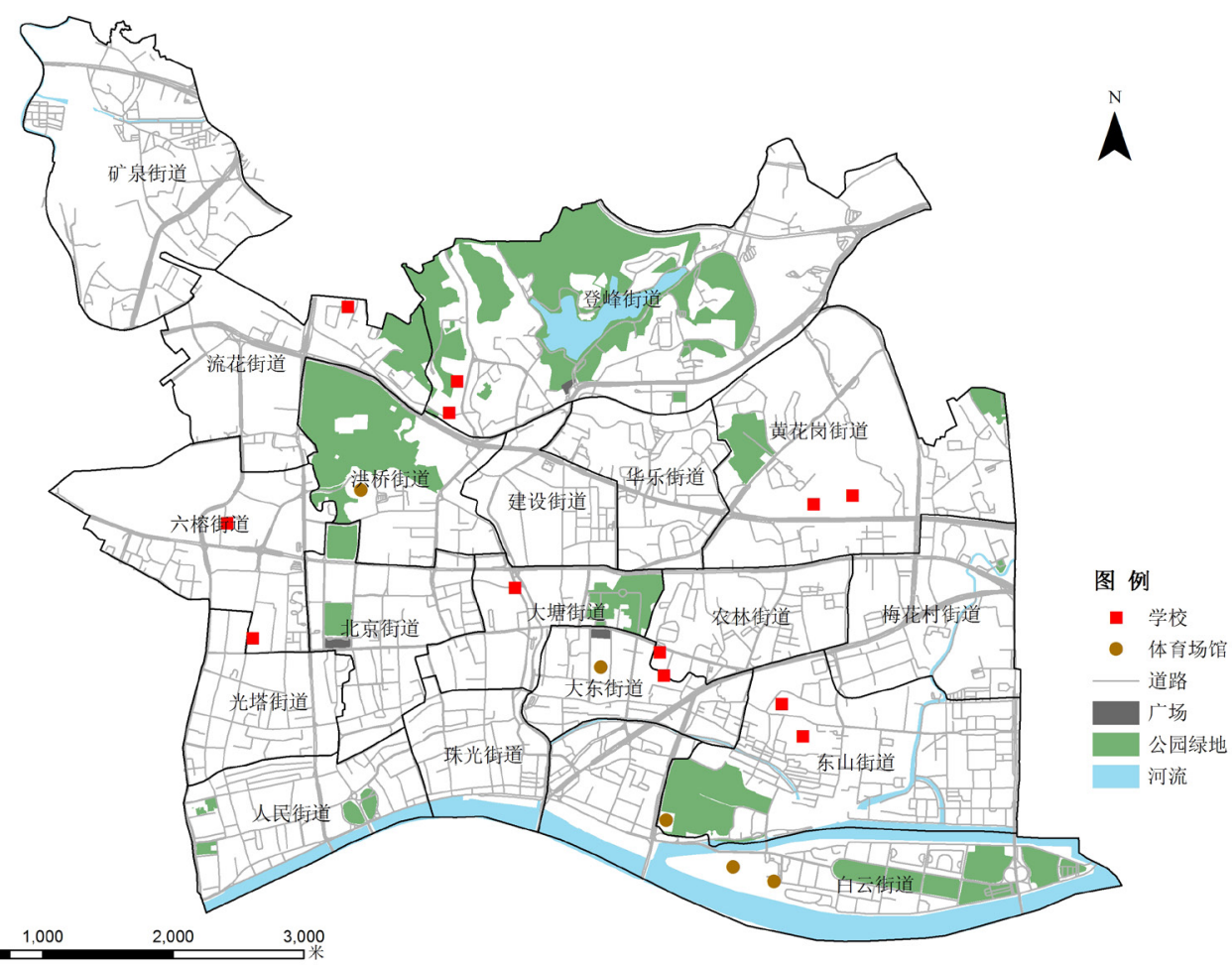

图 3. 广州越秀区现状应急避难场所资源空间分布 

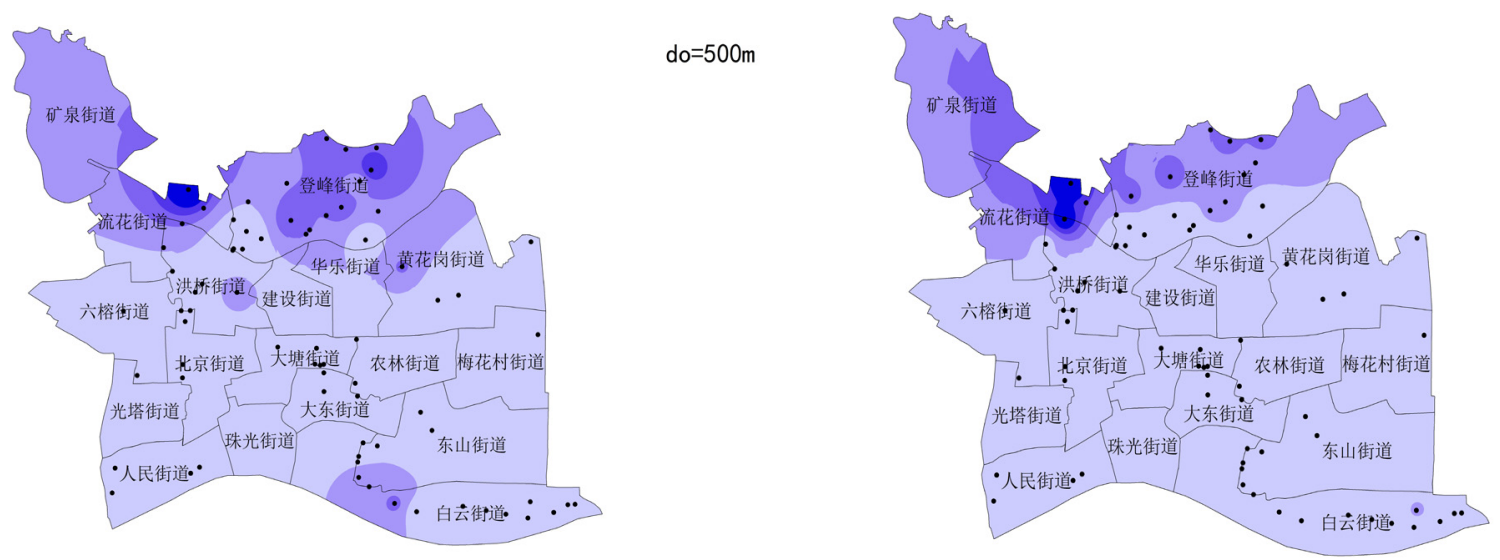

$\mathrm{do}=1000 \mathrm{~m}$

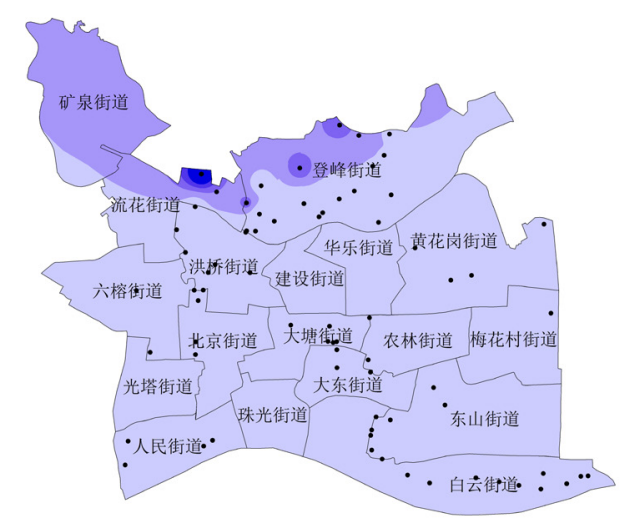

$\mathrm{do}=1500 \mathrm{~m}$

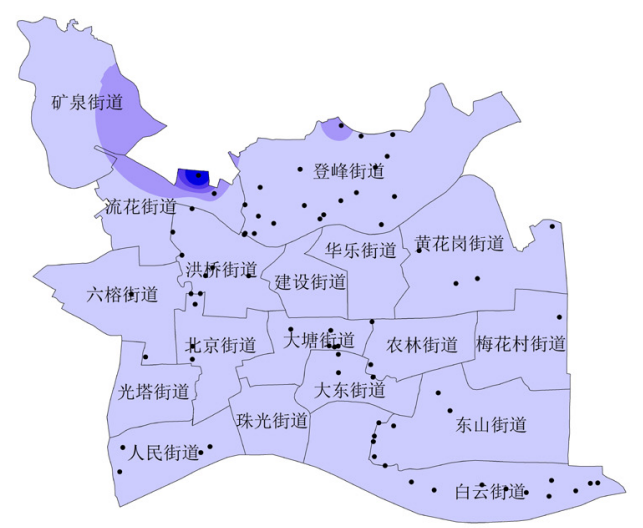

$\mathrm{do}=2000 \mathrm{~m}$

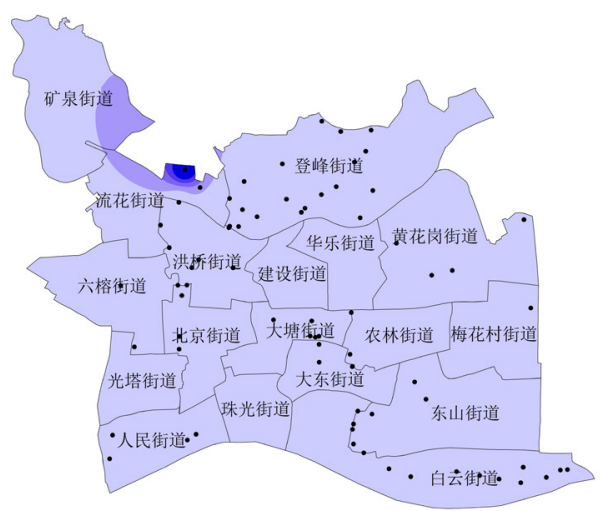

$\mathrm{do}=2500 \mathrm{~m}$

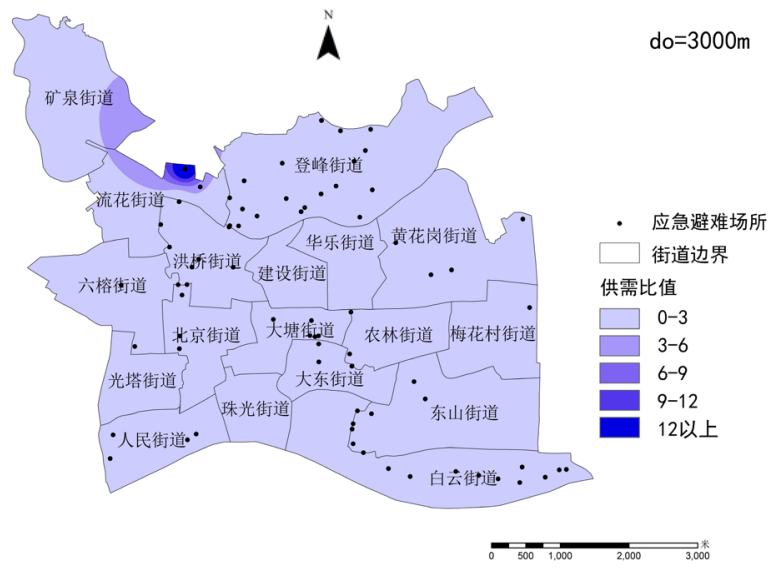

图 4. 不同阈值下越秀区应急避难场所供需比分布 


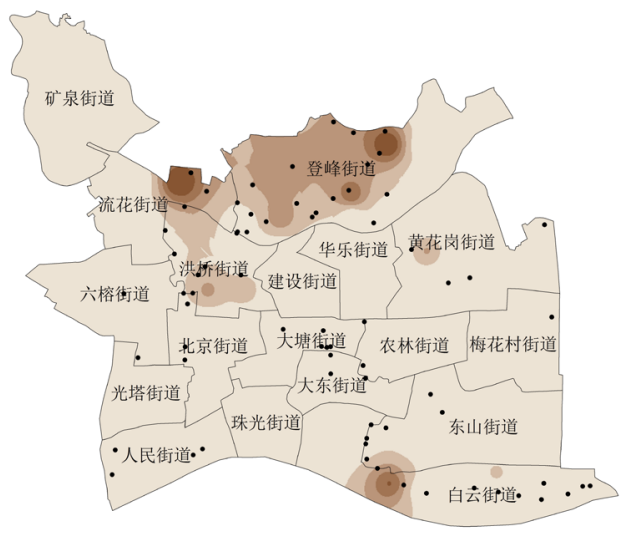

$\mathrm{do}=500 \mathrm{~m}$

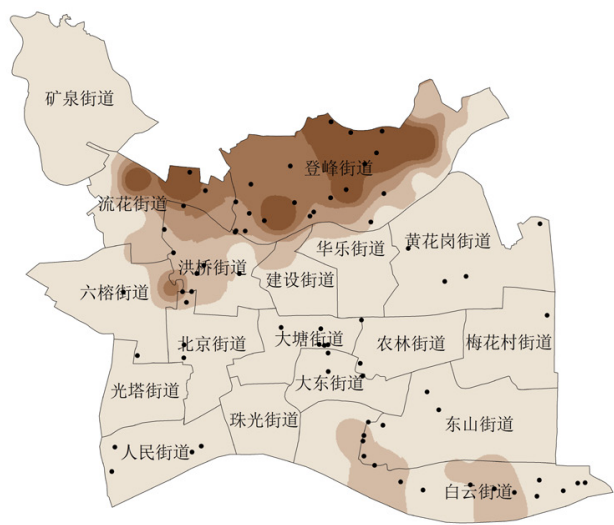

$\mathrm{do}=1000 \mathrm{~m}$

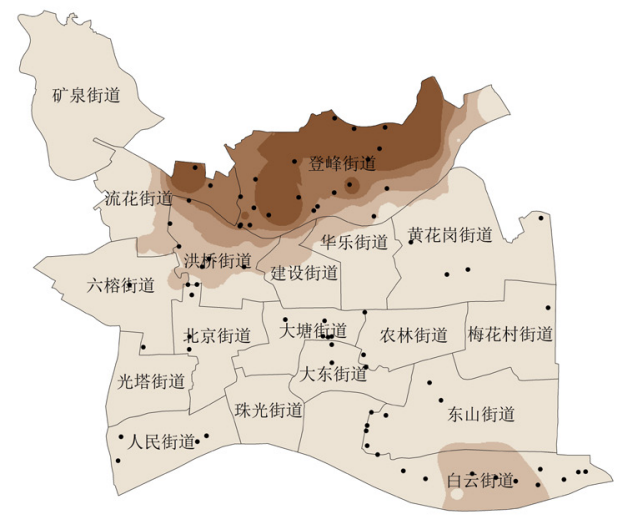

$\mathrm{do}=1500 \mathrm{~m}$

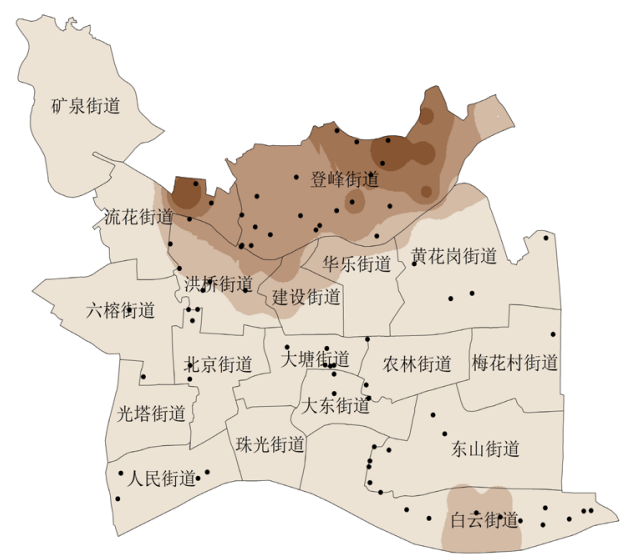

$\mathrm{do}=2000 \mathrm{~m}$

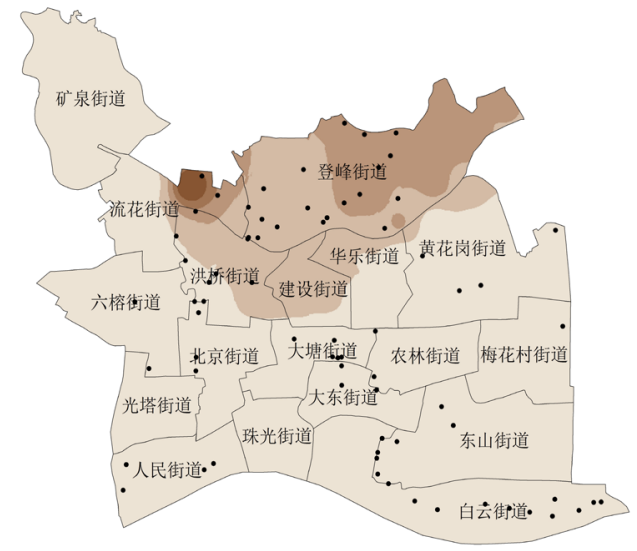

$\mathrm{do}=2500 \mathrm{~m}$

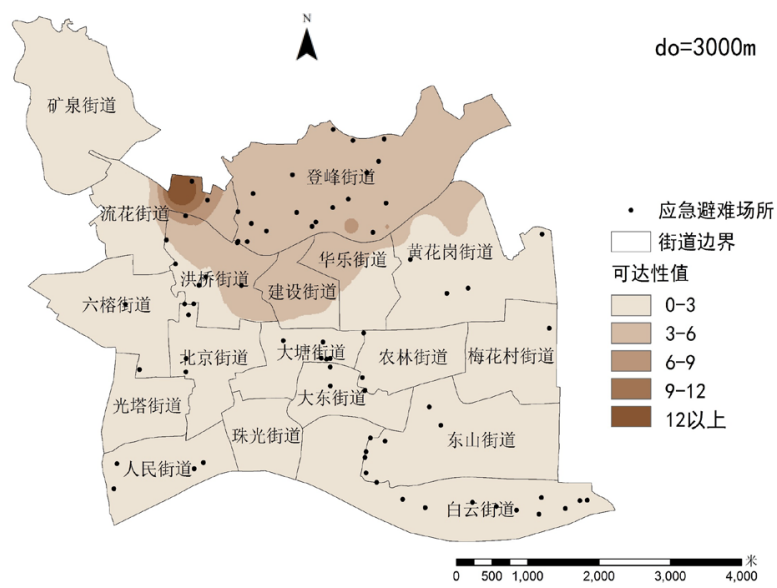

图 5. 不同阈值下越秀区应急避难场所可达性空间分布图 
表 2. 不同 $\mathrm{d}_{0}$ 条件下可达性值及服务面积比较

\begin{tabular}{|c|c|c|c|c|c|c|c|c|}
\hline & $0=500$ & & & $0=1000$ & & & $\mathrm{~d}_{0}=1500$ & \\
\hline \multirow{2}{*}{$A_{i}^{F}$} & 服务 & 比例 $(\%)$ & \multirow{2}{*}{$A_{i}^{F}$} & 服务 & 比例 $(\%)$ & \multirow{2}{*}{$A_{i}^{F}$} & 服务 & 比例 $(\%)$ \\
\hline & 面积 $\left(\mathrm{km}^{2}\right)$ & & & 面积 $\left(\mathrm{km}^{2}\right)$ & & & 面积 $\left(\mathrm{km}^{2}\right)$ & \\
\hline $0-3$ & 28.85 & $85.4 \%$ & $0-3$ & 25.16 & $74.44 \%$ & $0-3$ & 25.43 & $75.2 \%$ \\
\hline $3-6$ & 2.29 & $6.8 \%$ & $3-6$ & 3.76 & $11.12 \%$ & $3-6$ & 3.31 & $9.8 \%$ \\
\hline $6-9$ & 2.05 & $6.1 \%$ & $6-9$ & 1.23 & $3.64 \%$ & $6-9$ & 1.00 & $3.0 \%$ \\
\hline $9-12$ & 0.37 & $1.1 \%$ & $9-12$ & 1.91 & $5.65 \%$ & $9-12$ & 1.65 & $4.9 \%$ \\
\hline \multirow[t]{2}{*}{$>12$} & 0.21 & $0.6 \%$ & $>12$ & 1.73 & $5.12 \%$ & $>12$ & 2.38 & $7.0 \%$ \\
\hline & \multicolumn{2}{|l|}{$t_{0}=2000$} & \multicolumn{3}{|c|}{$\mathrm{d}_{0}=2500$} & \multicolumn{2}{|c|}{$\mathrm{d}_{0}=3000$} & \\
\hline \multirow{2}{*}{$A_{i}^{F}$} & 服务 & 比例 $(\%)$ & \multirow{2}{*}{$A_{i}^{F}$} & 服务 & 比例 $(\%)$ & \multirow{2}{*}{$A_{i}^{F}$} & 服务 & 比例 $(\%)$ \\
\hline & 面积 $\left(\mathrm{km}^{2}\right)$ & & & 面积 $\left(\mathrm{km}^{2}\right)$ & & & 面积 $\left(\mathrm{km}^{2}\right)$ & \\
\hline $0-3$ & 25.37 & $75.06 \%$ & $0-3$ & 25.89 & $76.6 \%$ & $0-3$ & 25.71 & $76.1 \%$ \\
\hline $3-6$ & 3.12 & $9.23 \%$ & $3-6$ & 4.87 & $14.4 \%$ & $3-6$ & 7.59 & $22.5 \%$ \\
\hline $6-9$ & 3.45 & $10.21 \%$ & $6-9$ & 2.78 & $8.2 \%$ & $6-9$ & 0.23 & $0.7 \%$ \\
\hline $9-12$ & 1.31 & $3.88 \%$ & $9-12$ & 0.10 & $0.3 \%$ & $9-12$ & 0.10 & $0.3 \%$ \\
\hline$>12$ & 0.50 & $1.48 \%$ & $>12$ & 0.13 & $0.4 \%$ & $>12$ & 0.13 & $0.4 \%$ \\
\hline
\end{tabular}

\section{4. 结论与建议}

\section{1 结论}

本文基于两步移动搜寻法和 GIS 空间分析法对广 州市越秀区应急避难场所进行空间可达性定量分析。 结果表明: 越秀区应急场所数量较多, 以公园绿地型 为主，同时人均应急避难场所面积基本能满足居民的 避难需求，但空间布局不够均衡和合理，各街道之间 供给比例差异显著; 应急避难场所可达性整体不高, 呈现出较大的南北差异, 北部的登峰街道和洪桥街道 可达性较好, 而北部街道和社区可达性较差; $1500 \mathrm{~m}$ 是越秀区应急避难场所的最佳服务半径, 该服务半径 下可达性最好，可达性好的服务面积比例最高。

\section{2 建议}

1）加快应急疏散路径规划。越秀区人口老年化严 重, 特殊人群较多, 同时商业密集, 人流车流拥挤, 建筑密度较高, 疏散路径规划过程中要重视疏散人群 的避难行为调查、避难空间分布和最优路径选择, 做 好人流、车流和应急标识的规划, 合理设计应急避难 通道。
2) 推进应急避难场所共享和管理。越秀区应急避 难场所可达性空间差异明显，为了提高社区整体应急 避难能力, 应充分利用周边的海珠区、白云区、黄埔 区应急避难场所, 实现资源共享, 满足就近避难的需 求。同时要加强应急避难场所运营和管理。根据 “平 灾结合” 的原则, 实现应急避难场所空间和设施的高 效转化。

致谢：本文得到了广东省高校重点平台及青年创新人 才项目（2015KQNCX226）; 中山大学新华学院科研 启动基金（2017QN001、2017YB002）的资助，在此 表示衷心感谢。

\section{参考文献}

[1] Abdulrahman B, Stephen G, Krisen M. An Overview of the Design of Disaster Relief Shelters [J]. Procedia Economics and Finance, 2014(18):924-931.

[2] 幸智慧,庄苏玲,陈达写.城市开敞空间的避难容灾能力 评价研究——深圳市南山区为例 [J].中国安全科学学 报,2011,21(3):150-155.

[3] 刘少丽,陆玉麒,顾小平,等.城市应急避难场所空间布局 合理性研究[J].城市发展研究,2012,19(3):113-120.

[4] Anhorn J, Khazai B. Open space suitability analysis for emergency shelter after an earthquake[J]. Natural Hazards and Earth System Science, 2015,15(4):789-803. 
[5] 钟少颖,杨金金,陈锐. 层级性公共服务设施空间可达性研 究——北京市综合性医疗设施为例 [J]. 地理研 究,2016,(4):731-744.

[6] Hansen W G. How accessibility shapes land use [J]. Journal of the American Institute of Planners, 1959(25): 73-76.

[7] Radke J,Mu L .Spatial decomposition, modeling and mapping service region to predict access to social programs $[\mathrm{J}]$.Geographic Information Sciences, 2000(6):105-112.

[8] 刘长富, 李小马, 韩东. 城市公园可达性研究方法与关 键问题[J]. 生态学报,2010,30(19):5381-5390.

[9] 王美霞, 蒋才芳, 王永明, 等. 基于公路交通网的武陵山片 区旅游景点可达性格局分析 [J]. 经济地 理,2014,34(6):187-192.
[10] 周爱华,张景秋,杜姗姗, 等. 一种北京城区避难场所可达 性评价方法[J].测绘科学,2017,42(1):88-92,106.

[11] 胡瑞山,董锁成,胡浩. 就医空间可达性分析的两步移动 搜索法: 以江苏省东海县为例. 地理科学进展, 2012, 31(12):1600-1607.

[12] 张培,张靖岩,王佳,朱立新. 城市社区应急避难场所区位 配 置 模型研 究 [J]. 中国安全科学学 报,2015,25(6):172-176.

[13] 唐波,丘飞鹏,黄嘉颖. 㓞性城市视角下中国应急避难场 所研究进展 [J]. 现代城市研究,2017,32(9):25-31.

[14] 周爱华,付晓. 基于两步移动搜寻法的北京城区应急避 难场所可达性研究 [J]. 安全与环境学 报,2013,13(6):250-253.

[15] 陶卓霖,程杨. 两步移动搜寻法及其扩展形式研究进展 [J]. 地理科学进展,2016,35(5):589-599. 